\title{
THE RELATIONSHIP BETWEEN THE CLINIC-BASED NUTRITION INSTRUCTIONS GIVEN TO NURSING MOTHERS AND THEIR COMPLEMENTARY FEEDING PRACTICES IN ENUGU STATE
}

\author{
Nwamarah, J.U. and Okeke, E.C. \\ Department of Home Science, Nutrition and Dietetics, \\ University of Nigeria, Nsukka, Nigeria.
}

\begin{abstract}
This study covered four different hospitals in Enugu State: University of Nigeria Teaching Hospital (UNTH), Mother of Christ Specialist Hospital (MCSH) both in Enugu and Comprehensive Health Centre (CHC), Bishop Shanahan Hospital both in Nsukka. This study ascertained the relationship between the clinic-based nutrition instructions given to the nursing mothers and their infant complementary feeding practices. Three hundred nursing mothers were randomly selected from the four hospitals. Validated questionnaires were used for data collection. There were uniformed infant nutrition instructions given to the nursing mothers by registered nurses in these selected baby-friendly hospitals. Pearson's product moment correlation $(r)$ analysis was used to obtain the correlation coefficients $(r)$. The study revealed that the relationship between the clinicbased infant nutrition education given to the nursing mothers and their complementary feeding practices were effective for the four hospitals but MCSH had the highest $r=0.68$ followed by UNTH $r=0.49$. The t-test result comparing the nursing mothers' infant complementary feeding practices in Enugu and Nsukka areas $(t=2.019)$ were significantly different at $5 \%$ probability level.
\end{abstract}

Key words: Nutrition instructions, complementary feeding practices, Nursing mothers

\section{INTRODUCTION}

Childhood malnutrition is a $\mathrm{m}$ or public health problem throughout the developin, world. Research conducted in a variety of settingstemonstrates that post natal growth faltering begins and six months of age, just as infants begin to receive foods to complement their breast milk intake (WHO/NUT, 1995; Okeke and Okafor, 1989). Interventions to address childhood malnutrition have shown that improving complementary feeding will reduce malnutrition. However, to address malnutrition and improve complementary feeding, attention must be given to decisions taken by mothers and caregivers about complementary feeding (Bereng et al., 2007). Again malnutrition as well as accelerating urbanization and commercialism, are leading to imbalances in availability of products and knowledge about nutrition. Nutrition education is an essential process for coping with these problems and issues (Jones et al., 1985).

The process of nutrition education may be defined as the teaching of validated, correct nutrition knowledge in ways that promote the development and maintenance of nutritive attitude toward and actual practical habits of eating nutritious food (Jones et al., 1985). Generally, the purpose of nutrition education is to create informed consumers who value good nutrition and consume nutritious foods throughout their lives and who subsequently pass on the information to others.

In most research evaluation studies in nutrition education one finds that knowledge, attitude and practices are the dependent or criteria's variables being measured. The foundations for this focus are strongly supported in educational theory (Jones et al.. 1985), and there has been some debate as to the extent that these three outcomes of nutrition education are related. Although several sociopsychological theories state that knowledge, attitudes and practice should be consistent, a number of studies indicate that their relationships are not simple or automatic (Bereng et al., 2007). Sellen (2001) observed that a combination of maternal selfperception, assessment of infant well-being, and indicators of household food supply influenced the actual progression of weaning for individual children. Seilen (2001) suggested that interventions to promote exclusive breastfeeding and improve complementary feeding practices did improve rural East African pastoral populations, because they emphasized on maternal attention to infant-centered cues and addressed household-level constraints on 


\section{DISCUSSION}

The correlation coefficient ( $r$ ) values were all positive. It could be inferred that infant nutrition instructions given to the nursing mothers were positively related to their infant complementary feeding practices. MCSH had the highest value $\mathrm{r}=0.68$ followed by UNTH with $r=0.49$ all in Enugu, thereby suggesting that nursing mothers who attended these child welfare clinics utilized the infant nutrition instructions given to them more than the nursing mothers who attended the other two clinics. The infant nutrition instructions were uniformly given by the registered nurses and these hospitals were also baby-friendly. This showed that knowledge alone does not always determine practice but is always determined by many motivations operating at the same time. There are a number of evaluations which provide credible evidence for the positive effects of education on health and nutrition practice. The factors which these evaluations have identified as contributing to successful practice change as mentioned below may have been observed by MSCH and UNTH for them to have successful practice change and high correlation values. The other two hospitals $\mathrm{CHC}$ and $\mathrm{BSH}$ must have ignored the factors hence the low correlation values of 0.08 and 0.07 , respectively. The factors are as follows: active involvement of learners in identifying their own needs (Parleto et al., 1982). Lee and Owen (1985), Zeitlin and Formacion (1981) noted that practice change must be seen as a process e.g. raising awareness of motivation does not automatically result in practice change. Lee and Owen (1985) and Whitehead (1979) pointed out that use of social networks by community organization and community leaders can support change. Cerqueira and Olsen (1995) on their part stated that information which allows for reasoned choice is preferable to didactic methods. Lee and Owen (1985) again stated that people are more likely to persist with actions if they find them enjoyable or rewarding. They also added that dependence on any particular place or person reduces the individual's capacity to take independent action. Therefore strategies selected to bring about practice change should be mediated by local knowledge and contexts.

The availability of trained personnel who understand and implement practice change strategies appropriately, and who can involve learners in solving their own nutrition problems is essential. To ensure a successful utilization of instructions by nursing mothers, demonstrations should be carried out for mothers to participate in using locally available and affordahle foodstufts.

The student $t$-test result comparing the complementary feeding practices of Enugu and Nsukka areas showed $t=2.019$ and was significantly different $P<0.05$. The urban environment, where the hospitals with a higher mean $(3.8 \pm 0.66)$ were sited could have an influence on the nursing mothers' complementary feeding practices. The competitive attitudes in urban areas could have played a role on the nursing mothers' complementary feeding practices, as well as the use of social networks in which there could have been peer group influences (Lee and Owen, 1985). External factors such as cultural expectations, food availability, food cost and financial status are all contributory factors (Church, 1982). Additionally, influences from television and radio adverts in the urban environment including the strategies used by the nurses may have caused the differences in complementary feeding practices of the nursing mothers from the different areas.

\section{CONCLUSION}

In conclusion the clinic-based nutrition instructions given to the nursing mothers by the registered nurses had some impact on the complementary feeding practices of the mothers. Hence the positive correlation values in all the hospital clinics. Some factors or strategies may have contributed to achieving high positive results in Enugu, which needed to be incorporated by the nurses in Nsukka area, so that their instructions could have a better impact on the nursing mothers that attended their hospital clinics.

There is also the need to create more health centres for nutrition instructions to be brought closer to the grassroot. Registered nurses should also have in-service training to acquaint themselves with current issues in their profession. Such training should serve as re-orientation with emphasis on infant complementary feeding. To ensure a successful utilization of instructions by nursing mothers, demonstrations should be carried out for mothers with their participation in using locally available and affordable foodstuffs. 


\section{REFERENCES}

Bereng, L., Bilkes, F. and Nxumalo, T.P. (2007). Patterns of decision-making on complementary feeding practices by caregivers of children aged 0 -36months in Hinkong and Klong sub-districts, Ratchaburi, Thailand. The Univ. of Queenland, Brisbane, Australia ABN 63 942 684, CRISCO provider No: 00025B.

Cerqueira, M.T. and Olsen, C.M. (1995). Nutrition in developing countries: an examination of recent successful projects. In $P$. Pinstrup- Andersen (ed.): Child growth and nutrition in developing countries. Ithaca, NY, Cornell University press. pp I-25.

Church, M.A. (1982). "Evaluation as an integral aspect of nutrition education" in B. Schürch (ed.) Evaluation of nutrition education in third world communities: A Nestlé Foundation workshop Lutry/Lausanne Hans Huber pub. Bern Sturtgart Vienne. pp 17-27.

Jones, D.Y., Meshiem, M.C. and Habitch, J.P. (1985). Influences of child growth associated with poverty: Cross-section United States National surveys. Am. J. Clin. Nutr. 42:714-717.
Lee, C. and Owen, N. (1985). "Behaviorally based-principles as guidelines for health promotion", community health studies. J.of Public Health Policy 10: 131-137

Okeke, E.C and Okafor, U.A. (1989). Current breast-feeding and Weaving practices in Anambra state. Nig. J. of Nutr. 10 (1): 21 30

Parleto, M., Green, C. and Fisherman, C. (1982). Communicating to improve nutrition behaviours: The challenge of motivating the audience to act. International conference on nutrition, Rome, FAO.

Sellen, D.W. (2001). Weaning, complementary feeding and maternal decision making in a rural East African pastoral population. J. of Human lactation. 17 (3): 233-244.

Whitehead, R.G. (1979). Infant feeding practices and the development ofmalnutrition in rural Gambia. Food Nutr. Bull. 1:39-41.

WHO/NUT (1995). Complementary feeding of infants and young children. Report of a technical consultation. $28-30^{\text {th }}$ November, 1995. World Health Organization Geneva pp23-24.

Zeitlin, M.F and Formacion, C.S. (1981). Nutrition intervention in developing countries. Study It: Nutrition education. Cambridge Massachusetts, Oelgeschlager, Gunn and Hain Pub. pp49-72. 
Inheritance of fruit colour in nigerian local okra. abelmoschus esrulentus (i.) Moench. cultivars.

Table. 2: Phenotypic expression of fruit skin colour in Parents, F1, F2 and backcross generations in okra

\begin{tabular}{|c|c|c|c|c|c|c|c|}
\hline Parents and Crosses & $\begin{array}{l}\text { Plants } \\
\text { with } \\
\text { Reddish } \\
\text { Green } \\
\text { colour }\end{array}$ & $\begin{array}{l}\text { Plants } \\
\text { with Deep } \\
\text { Green } \\
\text { colour }\end{array}$ & $\begin{array}{l}\text { Plants } \\
\text { with faint } \\
\text { greenish } \\
\text { milky } \\
\text { white } \\
\text { colour }\end{array}$ & $\begin{array}{l}\text { Total } \\
\text { population }\end{array}$ & $\begin{array}{l}\text { Expected } \\
\text { phenotypic } \\
\text { ratio }\end{array}$ & $x^{2}$ & Probability \\
\hline "Ogbu Oge" & 27 & $\cdots$ & - & 27 & & & \\
\hline Awgu Early & -- & 29 & -. & 29 & & & \\
\hline "Mpi Ele" & -- & -- & 24 & 24 & & & \\
\hline i) "Ogbu Oge" x Awgu Early, F1 & 30 & $-\cdot$ & -- & 30 & & & \\
\hline Awgu Early x "Ogbu Oge", Fl & 32 & - & -- & 32 & & & \\
\hline "Ogbu Oge" x Awgu Early, F2 & 155 & 47 & -- & 202 & $3: 1$ & 0.3233 & $.70 \cdot .50$ \\
\hline Awgu Early $x$ "Ogbu Oge" F2 & 142 & 39 & -- & 181 & $3: 1$ & 1.1510 & $.30-.20$ \\
\hline Awgu Early x ("Ogbu Oge" $x$ & & & & & & & \\
\hline Awgu Early) $\mathrm{BCI}$ & 27 & 35 & -- & 62 & $1: 1$ & 0.0322 & $.50 \cdot .30$ \\
\hline \multicolumn{8}{|l|}{ Awgu Early $x$ (Awgu Early $x$} \\
\hline "Ogbu Oge") BCl & 33 & 23 & - & 56 & $1: 1$ & 1.7857 & $.20-.10$ \\
\hline \multirow{5}{*}{\multicolumn{8}{|c|}{$\begin{array}{l}\text { ii) "Ogbu Oge" x "Mpi Ele", F1 } \\
\text { "Mpi Ele" x "Ogbu Oge". F1 } \\
\text { "Ogbu Oge" x "Mpi Ele", F2 } \\
\text { "Mpi Ele" x "Ogbu Oge" F2 } \\
\text { "Mpi Ele" x ("Ogbu Oge" x }\end{array}$}} \\
\hline & & & & & & & \\
\hline & & & & & & & \\
\hline & & & & & & & \\
\hline & & & & & & & \\
\hline “Mpi Ele") BCl & 24 & - & 31 & 55 & 1:1 & 0.8909 & $.50-.30$ \\
\hline \multicolumn{8}{|l|}{ "Mpi Ele" x ("Mpi Ele"x } \\
\hline "Ogbu Oge") BCl & 32 & -- & 27 & 59 & $1: 1$ & 0.4237 & $.70-.50$ \\
\hline iii) "Awgu Early x "Mpi Ele", Fl & -- & 21 & -- & 21 & & & \\
\hline "Mpi Ele" x Awgu Early, FI & - & 23 & -- & 23 & & & \\
\hline Awgu Early x "Mpi Ele" F2 & -- & 134 & 54 & 188 & $3: 1$ & 1.3900 & $.30-20$ \\
\hline "Mpi Ele" x Awgu Early F2 & -- & 135 & 58 & 193 & $3: 1$ & 2.6269 & $.20-.10$ \\
\hline "Mpi Ele" x (Awgu Early x & & & & & & & \\
\hline “Mpi Ele”) BCl & -- & 18 & 26 & 44 & $1: 1$ & 1.4545 & $.30-.20$ \\
\hline \multicolumn{8}{|l|}{ "Mpi Ele" x("Mpi Ele"x } \\
\hline Awgu Early) BCl & -- & 15 & 22 & 37 & 1:1 & 1.3243 & $.30-.20$ \\
\hline
\end{tabular}


Udengwu O.S.

Fig.1 Schematic Representation of Multiple Allelism in the Inheritance of Okra Fruit Skin Colour

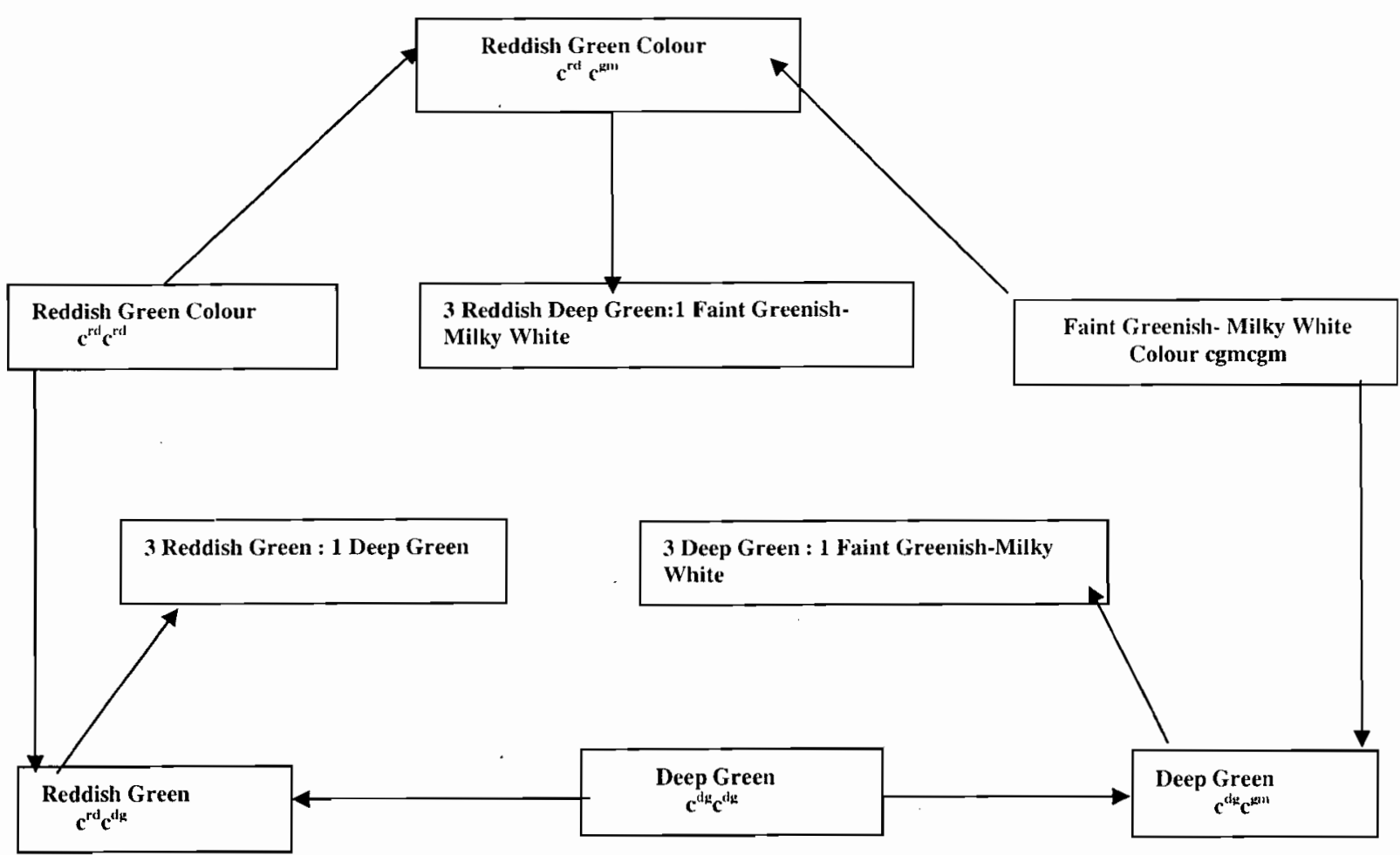

